This item was submitted to Loughborough's Research Repository by the author.

Items in Figshare are protected by copyright, with all rights reserved, unless otherwise indicated.

\title{
Do different kinds of user-generated content in online brand communities
} really work?

\section{PLEASE CITE THE PUBLISHED VERSION}

https://doi.org/10.1108/OIR-08-2016-0229

\section{PUBLISHER}

(C) Emerald

VERSION

AM (Accepted Manuscript)

\section{PUBLISHER STATEMENT}

This work is made available according to the conditions of the Creative Commons Attribution-NonCommercialNoDerivatives 4.0 International (CC BY-NC-ND 4.0) licence. Full details of this licence are available at: https://creativecommons.org/licenses/by-nc-nd/4.0/

\section{LICENCE}

CC BY-NC-ND 4.0

\section{REPOSITORY RECORD}

Estrella-Ramon, A., and Fiona Ellis-Chadwick. 2019. "Do Different Kinds of User-generated Content in Online Brand Communities Really Work?”. figshare. https://hdl.handle.net/2134/25080. 


\section{Do different kinds of user-generated content in online brand communities really work?}

\begin{tabular}{|r|l|}
\hline Journal: & Online Information Review \\
\hline Manuscript ID & OIR-08-2016-0229.R2 \\
\hline Manuscript Type: & Research Paper \\
\hline Keywords: & $\begin{array}{l}\text { User-generated content, Vividness and Richness of the content, Online } \\
\text { communities, Video games industry, Steam }\end{array}$ \\
\hline \multicolumn{2}{|c}{} \\
\hline
\end{tabular}

SCHOLARONE $^{\text {tw }}$

Manuscripts 


\title{
ONLINE INFORMATION REVIEW
}

\author{
Manuscript title: Do different kinds of user-generated content in online brand \\ communities really work? \\ Reference number: OIR-08-2016-0229.R1 \\ Modified version after considering the suggestions of the editors and referees
}

Sending date of the first version: $26 / 08 / 2016$

Sending date of the second version: $22 / 02 / 2017$

Sending date of the improved version: 08/05/2017

\section{Presentation of the changes in the article}

To begin with we would like to thank the editors and referees' comments that have led to an improvement of the article. We hope that the changes could satisfy the editors and referees requirements since they are considered to have enriched the article. Briefly, the main improvements of the new version are:

\section{$\underline{\text { EDITORS }}$}

Suggestion 1: In addition to what the reviewers are suggesting, we would like you to look at the recent literature to see if there is any new work that you would like to incorporate in this manuscript.

Before considering this editors' suggestion, we would like to indicate that we have corrected two erroneous references included in the last version of the paper. In particular, they are:

- An error in the year of publication in Floyd et al. (2015), which has been replaced by Floyd et al. (2014).

- An error in the surname of the author in Hyesun et al. (2016), which has been replaced by Jeon et al. (2016).

In addition, when we considered the suggestion number 1 of the first referee, related to the use of standardised variables in the empirical analysis, we checked the database in order to generate these standardised variables. During this process, we found a missing value in one of the video games considered (in particular, in the variable workshop presence). We apologize for this mistake that has been corrected for this new version of the paper, where we have used a final sample of 205 video games (we used a sample of 204 video games in the previous version).

Following the editors' suggestion related to the inclusion of new and recent references related to the topic discussed in the proposed paper, we have included the following ones (older references included in the previous version of the paper have been deleted in 
this last version in order to not exceed the maximum number of words allowed in the journal Online Information Review):

- Ailawadi, K.L and Farris, P.W. (2017), "Managing Multi-and Omni-Channel Distribution: Metrics and Research Directions", Journal of Retailing, Vol. 93 No. 1, pp. 120-135.

- Ballestar, M.T., Grau-Carles, P. and Sainz, J. (2016), "Consumer behavior on cashback websites: Network strategies", Journal of Business Research, Vol. 69 No. 6, pp. 2101-2107.

- Batra, R. and Keller, K.L. (2016), "Integrating Marketing Communications: New Findings, New Lessons, and New Ideas", Journal of Marketing, Vol. 80 No. 6, pp. 122-145.

- Chari, S., Christodoulides, G., Presi, C., Wenhold, J. and Casaletto, J. P. (2016), "Consumer Trust in User-Generated Brand Recommendations on Facebook", Psychology \& Marketing, Vol. 33 No. 12, pp. 1071-1081.

- Dessart, L., Veloutsou, C. and Morgan-Thomas, A. (2015), "Consumer engagement in online brand communities: a social media perspective", Journal of Product \& Brand Management, Vol. 24 No. 1, pp. 28-42.

- De Vries, L., Gensler, S. and Leeflang, P.S. (2012), "Popularity of brand posts on brand fan pages: An investigation of the effects of social media marketing", Journal of Interactive Marketing, Vol. 26 No. 2, pp. 83-91.

- Lamberton, C. and Stephen, A.T. (2016), “A Thematic Exploration of Digital, Social Media, and Mobile Marketing: Research Evolution from 2000 to 2015 and an Agenda for Future Inquiry", Journal of Marketing, Vol. 80 No. 6, pp. 146-172.

- Möller, K. (2013), "Theory map of business marketing: Relationships and networks perspectives", Industrial Marketing Management, Vol. 42 No. 3, pp. 324-335.

- Ringel, D.M. and Skiera, B. (2016), "Visualizing asymmetric competition among more than 1,000 products using big search data", Marketing Science, Vol. 35 No. 3, pp. 511-534.

- Sabate, F., Berbegal-Mirabent, J., Cañabate, A. and Lebherz, P.R. (2014), "Factors influencing popularity of branded content in Facebook fan pages", European Management Journal, Vol. 32 No. 6, pp. 1001-1011.

- Veloutsou, C., Aldas-Manzano, J. and Ruiz-Mafe, C. (2017), "The Dual Nature of Spreading Negative eWOM for Branded Offers: Emotional Reaction or Social Response? A Structured Abstract", in Stieler M. (Ed.), Creating Marketing Magic and Innovative Future Marketing Trends, Springer, Cham, pp. 471-476.

All changes are highlighted in yellow in the new version of the paper. We hope that these changes satisfy the editors and the referees.

\section{Suggestion 2: Please also ensure that in doing so your paper does not exceed the maximum word length of 8000 words.}

Following this editor's suggestion, the last version of this paper does not exceed the maximum number of words allowed by the editorial rules. In particular, the total number of words of each of the files included in this review is detailed below:

- Manuscript: 7,777 words. 
- Table 1: 123 words.

- Table 2: 68 words.

Therefore, the total number of words is: 7,968.

\section{REFEREE 1}

Suggestion 1: Authors describe the effect that low level, medium level and high level of UGC have on the number of owners in an isolated way, but they never face the analysis regarding if the higher the degree the higher/lower effect on adoption (positive or negative). It can be argued that the reader can derive his/her own conclusions from the results of the regression but (a) this is not exactly true as author/s provide non-standardized coefficients that are not directly comparable among them (they can be for most of the variables as units are the same, "number of..." but not for workshop presence that is a dummy variable) and (b) even in the case the reader could derive the conclusions on his/her own, a discussion would be recommendable. As a matter of example, can I conclude that the higher degree of vividness and richness the smaller number of adopters as the highest coefficient is negative (for workshop presence). I cannot. If you look at the coefficients it looks like the higher degree of vividness and richness the effect looks higher as they increase (both positive and negative values). I honestly believe this discussion is necessary.

With respect to this comment, we thank the referee for this observation that strengthens and clarifies the results obtained as well as the discussion and implications of the proposed research.

Following the referee's suggestion, in order to offer results that are directly comparable among them we have provided the standardised beta coefficients in the new version of the paper. Standardised beta coefficients are coefficients that we get if the variables in the regression were all converted to z-scores before running the analysis. Therefore, we have followed the procedure detailed in Bring (1994) in order to calculate standardised regression coefficients. This procedure implies the standardisation of all variables included in the model to be used in the regression analysis. We detailed the procedure followed to standardise all variables included in the proposed model is described below (Bring, 1994):

$$
\begin{aligned}
& x_{i}^{*}=\frac{x_{i}-\bar{x}_{i}}{s_{i}} \\
& y^{*}=\frac{y-\bar{y}}{s_{y}}
\end{aligned}
$$

Where $i=1, \ldots, \mathrm{k}, \bar{x}_{i}$ and $\bar{y}$ are the means of each variable in the sample and $s_{i}$ and $s_{y}$ are the standard deviations.

Once we have reviewed the empirical analysis, we have included some changes in the introduction, results and discussion sections, as well as in Table 2 (all the changes performed are highlighted in yellow in the new version of the paper). In order to 
facilitate the referee's review of these changes, we have included the new version of the Table 2 below.

Table 2. Ridge regression results

\begin{tabular}{lcc}
\hline Independent variables & $\boldsymbol{\beta}$ & S.E. \\
\hline $\begin{array}{l}\text { Number of positive } \\
\text { comments }\end{array}$ & $0.84^{*}$ & 0.24 \\
\hline $\begin{array}{l}\text { Number of negative } \\
\text { comments }\end{array}$ & $-0.76^{*}$ & 0.06 \\
\hline Number of discussions & $-0.82^{*}$ & 0.11 \\
\hline Number of screenshots & $0.17^{*}$ & 0.03 \\
\hline Amount of artwork & $0.49^{*}$ & 0.08 \\
\hline Number of videos & $-0.50^{*}$ & 0.08 \\
\hline Number of guides & $1.41^{*}$ & 0.13 \\
\hline Workshop presence & $-0.09^{*}$ & 0.02 \\
\hline Control variables & & \\
\hline Price & -0.03 & 0.02 \\
\hline $\begin{array}{ll}\text { Genre } \\
\text { Note: standardised } \beta \text { coefficients }\end{array}$ & 0.02 & 0.02 \\
\hline p $<0.01 ; *$ p $<0.05 ; * *$ p $<0.1$ & &
\end{tabular}

In addition, we also detailed some comments included in the new results and discussion sections, where we establish comparisons among the results obtained. Some examples included in the results section (on page 10) are:

- "... the positive effect of the number of positive comments is stronger than the negative effect of the number of negative comments on the number of owners".

- "... the negative effect of the number of discussions is stronger than the number negative comments on the number of owners".

- "... the positive effect of the number of artwork is stronger than the positive effect of the number of screenshots on the number of owners".

- "... the positive effect of the number of guides is stronger than the negative effect of the number of videos on the number of owners".

In addition, some comments included in the discussion section (on page 11) are:

- "... this study provides concrete ideas about the type of UGC within OBCs that significantly and positively predicts the success of products, such as the number of guides developed by users, positive comments, artwork and screenshots (in descending order)".

- "... this study also provides specific ideas about the type of UGC that significantly and negatively impacts the success of products, such as the number of discussions, negative comments, videos and workshop presence (in descending order)".

Finally, more comments are included in the managerial implications section (on pages 11-12), as follows: "... based on the results obtained, the type of UGC that exerts the highest positive effect on product success is the number of guides developed by users (characterised by a medium-high level of vividness and richness), while the number of discussions (characterised by a low level of vividness and richness) exerts the highest negative effect on product success". 
As a conclusion, in order to facilitate the referee's comparison of the standardised betas among the different independent variables, we summarised the results obtained in the following Table R1 (not included in the paper in order to not exceed the maximum number of words allowed in the journal Online Information Review).

Table R1. Summary of the results obtained

\begin{tabular}{|c|c|c|c|}
\hline Independent variables: & Effect & $\begin{array}{l}\text { Relative } \\
\text { strength }^{l}\end{array}$ & $\begin{array}{l}\text { Absolute } \\
\text { strength }^{2}\end{array}$ \\
\hline \multicolumn{4}{|c|}{ Low level of vividness and richness } \\
\hline Number of positive comments & + & $X$ & \\
\hline Number of negative comments & - & & \\
\hline Number of discussions & - & & $X(-)$ \\
\hline \multicolumn{4}{|c|}{ Low-medium level of vividness and richness } \\
\hline Number of screenshots & + & & \\
\hline Number of artworks & + & $X$ & \\
\hline \multicolumn{4}{|c|}{ Medium-high level of vividness and richness } \\
\hline Number of videos & - & & \\
\hline Number of guides & + & $X$ & $X(+)$ \\
\hline \multicolumn{4}{|l|}{ High level of vividness and richness } \\
\hline Workshop presence & - & $\mathrm{X}$ & \\
\hline \multicolumn{4}{|c|}{$\begin{array}{l}\text { Notes: } \\
{ }^{1} \text { Relative strength: comparisons among variables in the same category of vividness and richness } \\
\text { (in absolute value). } \\
{ }^{2} \text { Absolute strength: comparisons among all the variables included in the model (for }+ \text { and - } \\
\text { effects). }\end{array}$} \\
\hline
\end{tabular}

We hope that this explanation and the changes included in the new version of the paper satisfy the referee; otherwise we are open to further comments.

\section{REFEREE 2}

Suggestion 1: (a) My feeling is that it is more correct to write "video games" than "videogames". (b) Quotation in page 19 (Yadav and Pavlou, 2014 p. 26) should use brackets. (c) Proofreading is still needed (e.g., mediums instead of media in page 20).

We thank the referee for these observations related to the use of English language and quotations.

(a) We have to note that we have replaced "videogames" by "video games" but we have used only "games" in some parts of the paper.

(b) In addition, we have enclosed in quotes ("') the quotations:

- (Yadav and Pavlou, 2014, p. 26) located on page 2 of the paper.

- (Bagozzi and Dholakia, 2006, p. 45) located on page 3 of the paper. 
(c) Finally, the paper has been checked by a native copy editor in order to correct language mistakes.

As a conclusion we have to note that all the requested changes are included in the new version of the paper highlighted in yellow in order to be easily recognised by the referee. In addition, we hope that these comments and changes satisfy the referee.

Suggestion 2: I think that more specific managerial implications can be drawn from the results. If "in this research it has been clearly shown that the content that users generate around a product in OBCs makes significant differences on product success depending on the format of this content" and "companies should consider paying attention to the different types of UGC in order to achieve the greatest positive outcome from their investment in their presence in OBCs"; don't you think that brand managers should respond to this encouraging OBCs users to create UGC that positively impacts product success (for example, positive low level of vividness and richness comments via contests, etc.)?

Following this referee's suggestion, we have included more specific managerial implications in the last version of the paper (changes are highlighted in yellow) specifying the idea suggested by the referee: "brand managers should encourage OBCs users to create UGC that positively impacts product success". We have included below the new contents included in this section.

"Understanding the relationship between consumers and brands in OBCs has powerful managerial implications as the sharing of personal views and opinions of brands in OBCs have an ever-increasing influence on other customers (Wang et al., 2011). Therefore, managers should consider paying attention to the different types of UGC in order to achieve the greatest positive outcome from their presence in OBCs. With the aim of helping managers in this task, this research proposes and tests a framework including a comprehensive typology of UGC based on richness and vividness concepts. Thus, the proposed framework can help managers to better understand the diversity of messages that can be used in OBCs. Additionally, this research offers an analytical tool for assessing the impact of different types of UGC on product success. In particular, based on the results obtained, the type of UGC that exerts the highest positive effect on product success is the number of guides developed by users (characterised by a medium-high level of vividness and richness), while the number of discussions (characterised by a low level of vividness and richness) exerts the highest negative effect on product success. Finally, the findings of this research suggest managers focus their marketing efforts regarding OBCs on encouraging consumers to create the type of UGC that most positively affects product success".

We hope that these changes satisfy the referee; otherwise we are open to further comments.

\section{FINAL COMMENTS FROM AUTHORS}

Finally, we would like to express our sincere gratitude and appreciation to the editors and referees whose suggestions have contributed to enhance the article. Furthermore, 
we hope that the changes incorporated in the new version will meet the editors and referees' requirements.

Taking into consideration our aim of publishing the article in ONLINE INFORMATION REVIEW would be favourable, we will be open to any further comments estimated.

\section{References used in this review}

Ailawadi, K.L and Farris, P.W. (2017), "Managing Multi-and Omni-Channel Distribution: Metrics and Research Directions", Journal of Retailing, Vol. 93 No. 1, pp. 120-135.

Ballestar, M.T., Grau-Carles, P. and Sainz, J. (2016), "Consumer behavior on cashback websites: Network strategies”, Journal of Business Research, Vol. 69 No. 6, pp. 2101-2107.

Batra, R. and Keller, K.L. (2016), "Integrating Marketing Communications: New Findings, New Lessons, and New Ideas”, Journal of Marketing, Vol. 80 No. 6, pp. 122-145.

Bring, J. (1994), "How to standardize regression coefficients", The American Statistician, Vol. 48 No. 3, pp. 209-213.

Chari, S., Christodoulides, G., Presi, C., Wenhold, J. and Casaletto, J. P. (2016), “Consumer Trust in User-Generated Brand Recommendations on Facebook", Psychology \& Marketing, Vol. 33 No. 12, pp. 1071-1081.

Dessart, L., Veloutsou, C. and Morgan-Thomas, A. (2015), "Consumer engagement in online brand communities: a social media perspective", Journal of Product \& Brand Management, Vol. 24 No. 1, pp. 28-42.

De Vries, L., Gensler, S. and Leeflang, P.S. (2012), "Popularity of brand posts on brand fan pages: An investigation of the effects of social media marketing", Journal of Interactive Marketing, Vol. 26 No. 2, pp. 83-91.

Lamberton, C. and Stephen, A.T. (2016), "A Thematic Exploration of Digital, Social Media, and Mobile Marketing: Research Evolution from 2000 to 2015 and an Agenda for Future Inquiry", Journal of Marketing, Vol. 80 No. 6, pp. 146-172.

Möller, K. (2013), "Theory map of business marketing: Relationships and networks perspectives”, Industrial Marketing Management, Vol. 42 No. 3, pp. 324-335.

Ringel, D.M. and Skiera, B. (2016), "Visualizing asymmetric competition among more than 1,000 products using big search data”, Marketing Science, Vol. 35 No. 3, pp. 511-534.

Sabate, F., Berbegal-Mirabent, J., Cañabate, A. and Lebherz, P.R. (2014), "Factors influencing popularity of branded content in Facebook fan pages", European Management Journal, Vol. 32 No. 6, pp. 1001-1011. 
Veloutsou, C., Aldas-Manzano, J. and Ruiz-Mafe, C. (2017), "The Dual Nature of Spreading Negative eWOM for Branded Offers: Emotional Reaction or Social Response? A Structured Abstract", in Stieler M. (Ed.), Creating Marketing Magic and Innovative Future Marketing Trends, Springer, Cham, pp. 471-476.

Wang, Y.J., Butt, O.J., and Wei, J. (2011), "My identity is my membership: A longitudinal explanation of online brand community members' behavioural characteristics", Journal of Brand Management, Vol.19 No. 1, pp 45-56.

\section{New references included in the paper}

Ailawadi, K.L and Farris, P.W. (2017), "Managing Multi-and Omni-Channel Distribution: Metrics and Research Directions", Journal of Retailing, Vol. 93 No. 1, pp. 120-135.

Ballestar, M.T., Grau-Carles, P. and Sainz, J. (2016), "Consumer behavior on cashback websites: Network strategies”, Journal of Business Research, Vol. 69 No. 6, pp. 2101-2107.

Batra, R. and Keller, K.L. (2016), "Integrating Marketing Communications: New Findings, New Lessons, and New Ideas", Journal of Marketing, Vol. 80 No. 6, pp. 122-145.

Chari, S., Christodoulides, G., Presi, C., Wenhold, J. and Casaletto, J. P. (2016), "Consumer Trust in User-Generated Brand Recommendations on Facebook", Psychology \& Marketing, Vol. 33 No. 12, pp. 1071-1081.

Dessart, L., Veloutsou, C. and Morgan-Thomas, A. (2015), "Consumer engagement in online brand communities: a social media perspective", Journal of Product \& Brand Management, Vol. 24 No. 1, pp. 28-42.

De Vries, L., Gensler, S. and Leeflang, P.S. (2012), "Popularity of brand posts on brand fan pages: An investigation of the effects of social media marketing", Journal of Interactive Marketing, Vol. 26 No. 2, pp. 83-91.

Lamberton, C. and Stephen, A.T. (2016), “A Thematic Exploration of Digital, Social Media, and Mobile Marketing: Research Evolution from 2000 to 2015 and an Agenda for Future Inquiry”, Journal of Marketing, Vol. 80 No. 6, pp. 146-172.

Möller, K. (2013), "Theory map of business marketing: Relationships and networks perspectives", Industrial Marketing Management, Vol. 42 No. 3, pp. 324-335.

Ringel, D.M. and Skiera, B. (2016), "Visualizing asymmetric competition among more than 1,000 products using big search data”, Marketing Science, Vol. 35 No. 3, pp. 511-534.

Sabate, F., Berbegal-Mirabent, J., Cañabate, A. and Lebherz, P.R. (2014), "Factors influencing popularity of branded content in Facebook fan pages", European Management Journal, Vol. 32 No. 6, pp. 1001-1011. 
1

2

3

4

5

6

7

8

9

10

11

12

13

14

15

16

17

18

19

20

21

22

23

24

25

26

27

28

29

30

31

32

33

34

35

36

37

38

39

40

41

42

43

44

45

46

47

48

49

50

51

52

53

54

55

56

57

58

59

60

Veloutsou, C., Aldas-Manzano, J. and Ruiz-Mafe, C. (2017), “The Dual Nature of Spreading Negative eWOM for Branded Offers: Emotional Reaction or Social Response? A Structured Abstract", in Stieler M. (Ed.), Creating Marketing Magic and Innovative Future Marketing Trends, Springer, Cham, pp. 471-476. 


\title{
Do different kinds of user-generated content in online brand communities really work?
}

\begin{abstract}
Purpose - Due to the fact that user-generated content and online brand communities are gaining popularity, the purpose of this study is to identify the type of user-generated content that has a real effect on product success, in terms of the number of owners, within a popular online brand community associated with video games.

Design/methodology/approach - Different types of user-generated content for 205 video games were manually collected (the number of positive and negative comments, discussions, screenshots, artwork, videos, guides developed by users, and the presence of a workshop) to test their influence on product success. The proposed hypotheses were tested using multiple ridge regression analysis.

Findings - Results show that users look for simple and quick reviews and content about products in online brand communities (i.e., guides developed by users, comments, artwork and screenshots). However, results also show that users do not guide their purchases based on usergenerated content when the process of gaining understanding is more time-consuming (i.e., reading discussions, watching videos) or requires more active involvement (i.e., workshop presence).

Originality/value - Limited research has been conducted on the type of user-generated content found in online brand communities. This study contributes to the understanding of the potential influence of different types of user-generated content on product success. In addition, it offers managerial insights for companies into how to manage content in online communities.
\end{abstract}

Keywords User-generated content, Vividness and Richness of the content, Online communities, Video games industry, Steam

Paper type Research paper

\section{Introduction}

The video game industry has grown considerably over the past decade, demonstrating resilience and flexibility with regard to the economic crisis that began in 2008. In that same year, worldwide sales in this sector (including hardware and software) surpassed $\$ 50$ billion (more than double the annual sales in 2004, 2005, and \$5 billion more than in 2007) (Wesley and Barczak, 2016). This increase in sales growth has continued and by 2016 recorded sales reached $\$ 74$ billion (Statista, 2016). Video games should no longer be viewed as the exclusive domain of antisocial teenagers but rather as a form of media that has occupied an important position among mainstream media in terms of participation and revenues. Their impact on society is farreaching, creating new forms of interaction among users, for example through online brand communities (OBCs), and also influencing technology advances (e.g., artificial intelligence, computer graphics). Indeed, communication scholars have noted that video games are now one of the leading forms of media consumption, with sales rivalling the most successful Hollywood blockbusters (Wesley and Barczak, 2016). Nevertheless, OBCs and user-generated content (UGC) related to video games remain largely unexplored by scholars.

Given the continuous global expansion of the Internet, new opportunities and challenges have emerged for brands and products (Bellman et al., 2006). Initially, marketers used the Internet as 
a way to communicate with customers, and even to engage them in two-way communication (Lamberton and Stephen, 2016). However, consumers also began to communicate with each other through virtual communities (i.e., social networks) and OBCs (Dessart et al., 2015). This development in how marketers and consumers interact led to an important shift in the type of content generated in OBCs. More specifically, this shift involved an evolution from primarily simple text-based UGC to newer types of complex multimedia content (e.g., pictures, videos). As a result, "the generation and management of such multimedia collections are more complex than only textual content" (Yadav and Pavlou, 2014, p. 26). Despite the importance of understanding the effects of different types of UGC in OBCs on brand/product success, this topic has received limited attention in academic literature (Lamberton and Stephen, 2016; Yadav and Pavlou, 2014). Previous research is mainly focused on volume and/or valence of customers' reviews (i.e., only text based), obtaining mixed results on their influence on sales (Floyd et al., 2014; You et al., 2015) and other psychological outcomes (Purnawirawan et al., 2015). Moreover, previous research focused on the analysis of different types of UGC merely examines their influence on brand popularity (de Vries et al., 2012; Sabate et al., 2014) and brand engagement (Coursaris et al., 2016; Luarn et al., 2015). Therefore, this research uses the video games industry in order to investigate the impact that a wide set of different types of UGC found in OBCs has on product success. By doing so, this work fulfils this research gap in the literature.

The purpose of this study is to provide a better understanding of the virtual communities phenomenon, testing whether the different kinds of UGC will have a real effect on product success (in terms of the number of owners) within a popular OBC associated with video games: Steam ${ }^{1}$. In this way, this research addresses the following question: Do different kinds of UGC in OBCs influence product success? Based on previous literature, hypotheses are developed regarding the type of UGC found in OBCs. Data were manually collected for 205 video games from Steam (the OBC itself, developed by Valve Corporation) and Steamspy (a stats service based on a Web Application Programming Interface -API- provided by Valve Corporation). A multiple ridge regression analysis was conducted to test the hypotheses, and it revealed the significant impact of the different types of UGC on product success. More specifically, the number of guides developed by Steam users, positive comments, artwork and screenshots are positively associated with product success. In contrast, the number of discussions, negative comments, videos and workshop presence have a negative impact on product success. These results have significant implications for academic theory and practice.

\section{Literature review}

Previous literature related to marketing in computer-mediated environments is organised into four key areas: interactions between customer-firm, firm-customer, firm-firm and customercustomer (Yadav and Pavlou, 2014). The first key area of research, customer-firm interactions, is focused on network navigation (e.g., Ballestar et al., 2016), technology-enabled search (e.g., Huang et al., 2009), and technology enabled decision-making (e.g., Cotte and LaTour, 2009). The second area, firm-customer interactions, is focused on marketing mix decisions pertaining to the product (e.g., Ringel and Skiera, 2016), integrated marketing communication (e.g., Batra

\footnotetext{
${ }^{1}$ Steam is chosen for this research because of the number of Steam users around the world, there were approximately 175 million in 2016, up from 130 million the previous year (PCGamer, 2016).
} 
and Keller, 2016), pricing (e.g., Zhang and Wedel, 2009), and multichannel management (e.g., Ailawadi and Farris, 2017). The third main area, firm-firm interactions, is focused on interorganizational networks (e.g., Möller, 2013), competition (e.g., Pazgal and Soberman, 2008), and business-to-business auctions (e.g., Wilbur and Yi, 2009). Finally, the customercustomer interactions area comprises research focused on consumer behaviour related to customers' interactions with other customers. Some examples are related to social networks and OBCs (e.g., Dessart et al., 2015), and even UGC created within these sites (e.g., Jeon et al., 2016). This area of literature is the selected topic for fulfilling the research gap with regard to understanding the effects of different types of UGC in OBCs.

\subsection{Online brand communities (OBCs)}

A brand community is a social space where information and experiences about a specific brand are shared among users, or between users and the brand (Dessart et al., 2015; Jeon et al., 2016). More specifically, a brand community is defined as "any group of consumers with a shared enthusiasm for the brand and a well-developed social identity, whose members engage jointly in-group actions to accomplish collective goals and/or express mutual sentiments and commitments" (Bagozzi and Dholakia, 2006, p. 45). Brand communities are found not only offline (e.g., Harley Davidson owners), but also in online environments (Stokburger-Sauer, 2010).

Previous research on OBCs has focused attention on the identification of those characteristics that lead consumers to value brand communities and participate in communal activities (Stokburger-Sauer, 2010), the effect of this participation on brand identification and involvement (Chang et al., 2013), satisfaction with brands and brand loyalty (Stokburger-Sauer, 2010), or consumer engagement (Dessart et al., 2015). Customers' participation in OBCs also affects performance measures, such as brand purchase (Steinman et al., 2015), new products success (Gruner et al., 2014), and sales (Adjei et al., 2010). However, there is still a lack of research analysing the real effect of different kinds of UGC developed in OBCs on these performance measures, which is precisely the goal of the proposed research.

\subsection{User-generated content (UGC)}

UGC is "published content on a publicly accessible website or on a social networking site that needs to show a certain amount of creative effort, and it has been created outside of professional routines and practices" (Kaplan and Haenlein, 2010, p. 61). It can be developed by individuals or collaboratively, as well as produced, modified, shared and consumed. It essentially represents the sum of all ways in which people make use of OBCs and other media such as social networks (Kaplan and Haenlein, 2010). UGC is related (i.e., broader than) but not identical to electronic word-of-mouth (e-WOM). e-WOM can be defined as any positive or negative statement made by potential, actual or former customers about a product or company which is made available to a multitude of people and institutions via the Internet (Hening-Turau et al., 2004). UGC and eWOM are similar when they are found in OBCs and are related to the brand itself or the products it offers (Smith et al., 2012).

Three relevant research streams on brand-related UGC can be found in previous literature (Smith et al., 2012). The first investigates consumer-generated advertisements and brands, for example, what motivates customers to create certain kinds of content, and how the process of 
co-creation can be managed (e.g., Berthon et al., 2008; Burmann, 2010). The second analyses how credible consumers find UGC and their goals for engaging with such content (e.g., Chari et al., 2016). Finally, the third research stream focuses on the relationship between UGC and significant managerial outcomes, such as sales (e.g., You et al., 2015), the economic value of posts in online settings (e.g., Ghose and Ipeirotis, 2009), brand engagement (e.g., Luarn et al., 2015) or user reactions (e.g., Jeon et al., 2016). However, none of the previous research related to this third research stream is focused on understanding how different kinds of UGC differ in their relationship with performance measures (e.g., product success in terms of number of owners of products). In contrast, this is the main goal of the present study.

Furthermore, when people are motivated to communicate something about a brand or product through UGC in OBCs, they rely on a range of communication strategies to construct and project their opinions and views. In this regard, users' posts on OBCs sometimes contain images, photos, videos, or links to other pages. These different types of UGC in OBCs make posts more or less vivid (Jeon et al., 2016; Luarn et al., 2015), and rich (Coursaris et al., 2016). Vividness refers to "the ability of a technology to produce a sensorially rich mediated environment" (Steuer, 1992, p. 80). Based on this definition by Steuer, vividness is conceptualized in this study as the extent to which a post stimulates various senses. Compared with information in only text messages, information depicted in images or videos can provide users with more vivid details about a product (Jeon et al., 2016; Luarn et al., 2015). Therefore, multimedia content has the potential to be more attractive for users because of its direct impact on various senses (Coyle and Thorson, 2001). Similarly, the Media Richness theory (Daft and Lengel, 1986) assumes that the media are developed in a continuum allowing different feedback, information capacity, and information personalization in order to deliver more or less complex messages. Following this theory, each medium, or the way a message is transferred, may differ in its uncertainty and equivocality (Jeon et al., 2016). Accordingly, a richer medium is one that allows users to transfer or disseminate information with less uncertainty and equivocality (Kaplan and Haenlein, 2010). As an illustration of a richer message, videos can provide more helpful information on playing games (i.e., demos or playing instructions) than a static two-dimensional image (Jeon et al., 2016; Rauschnabel et al., 2012). Therefore, this research analyses the impact of different kinds of UGC found in OBCs in terms of vividness and richness on the product success.

\section{Hypotheses development}

Different kinds of UGC are characterised by vividness and richness, and these two dimensions can be divided into four different levels. Low level of vividness and richness comprises positive and negative comments and discussions. Low-medium level of vividness and richness comprises screenshots and artwork. Medium-high level of vividness and richness comprises videos and game guides developed by users. Finally, high level of vividness and richness comprises the presence of a workshop within the online space of the game within Steam (where users can design, develop and offer other users elements to be used in the game). Figure 1 illustrates the overall research model.

[Figure 1. Research model]

Low level vividness and richness: positive and negative comments and discussions 
From the perspective of vividness and richness of online UGC, reviews and comments are only text messages and are characterised as low level of vividness and richness (Coursaris et al., 2016; Luarn et al., 2015). Previous research obtains mixed results regarding the influence of valence of users' reviews (i.e., whether comments are positive or negative) on sales (Floyd et al., 2014; You et al., 2015) and other psychological outcomes (Purnawirawan et al., 2015). Despite this fact, some authors underscore the significance of online customers' reviews by showing that positive/negative information encountered online can be a triggering factor to modify customer behaviour (i.e., buy/not buy, respectively) (Adjei et al., 2010; Chevalier and Mayzlin, 2006; Veloutsou et al., 2017). In particular, positive e-WOM (in the form of text messages) includes favourable experiences and recommendations for buying certain products, while negative e-WOM refers to unfavourable experiences and recommendations for not buying certain products, motivated primarily by a desire to address a perceived injustice (Luo, 2009). As has been previously noted, UGC is broader than e-WOM, but the two overlap considerably when UGC is found in an OBC and is related to that brand or the products that it offers (Smith et al., 2012). Therefore, we can state that positive e-WOM (i.e., positive comments in this research) can motivate purchases while negative e-WOM (i.e., negative comments) can inhibit them, which leads to the following hypotheses:

H1a. UGC in OBCs in the form of positive comments about a product has a positive impact on the number of owners of that product.

H1b. UGC in OBCs in the form of negative comments about a product has a negative impact on the number of owners of that product.

Discussions developed by users in the forum section of OBCs are also characterised as low level of vividness and richness in this research, mainly because the content found in these discussions is text based (Coursaris et al., 2016; Luarn et al., 2015). Previous research offers evidence about the role of UGC in forums/discussions in performance measures, such as product adoption. For example, Thompson and Sinha (2008) find that higher levels of participation in discussions/forums of new products (i.e., generating more UGC) increase the adoption rate of these products. Following this rationale, we can suggest that when customers create and/or find more discussions about a product in an $\mathrm{OBC}$, this can act as an incentive or motivation to acquire that product from its brand. Therefore, we propose the following research hypothesis:

H2. UGC in OBCs in the form of discussions about a product has a positive impact on the number of owners of that product.

\section{Low-medium level of vividness and richness: screenshots and artwork}

From the point of view of vividness and richness of online UGC, previous research proposes that, compared with UGC comprised of only text, information containing pictures and photos can provide users with more vivid and richer information about a product (Coursaris et al., 2016; Luarn et al., 2015). Therefore, in general, as UGC in OBCs has been proven to be a good predictor of sales (Adjei et al., 2010; Chevalier and Mayzlin, 2006) and the adoption of new products (Gruner et al., 2014; Thompson and Sinha, 2008), the present study considers that UGC characterised by more vividness and richness than simply text (i.e., graphic UGC in the form of screenshots and artwork) also has a positive effect on product success. Thus, the following research hypotheses are proposed: 
H3. UGC in OBCs in the form of screenshots of a product has a positive impact on the number of owners of that product.

H4. UGC in OBCs in the form of artwork of a product has a positive impact on the number of owners of that product.

Medium-high level of vividness and richness: videos and guides developed by users

Videos and guides developed by users, characterised as having a medium-high level of vividness and richness, can show users demonstrations or playing instructions that are hard to express in terms of merely static text or images (Rauschnabel et al., 2012). Previous research proposes that this medium level of vividness and richness content has a positive impact on the reaction of users to this content (Jeon et al., 2016) and attracts more people (Xu et al., 2009). As it has been demonstrated that attractiveness is a good predictor of purchase intention (Saboo $e t$ al., 2015), UGCs characterised by a medium-high level of vividness and richness (i.e., videos and guides developed by users) are herein also considered to exert a positive influence on product success. Thus, the following research hypotheses are proposed:

H5. UGC in OBCs in the form of videos showing a product has a positive impact on the number of owners of that product.

H6. UGC in OBCs in the form of guides about a product has a positive impact on the number of owners of that product.

High level of vividness and richness: workshop presence

According to previous studies, a high degree of vividness and richness appears to be most effective in enhancing attitudes towards a web site (Coyle and Thorson, 2001; Fortin and Dholakia, 2005), increasing click-through rates (Lohtia et al., 2007), and even strengthening customer engagement on social network sites (Coursaris et al., 2016; Luarn et al., 2015). As customer engagement in OBCs and attitudes towards a web site have been previously linked to both intention to purchase and sales (Kumar et al., 2016; Mutaz et al., 2015), it is herein considered that UGCs characterised by a high level of vividness and richness (i.e., workshop presence) also play an important role in product success. Thus, it is proposed:

H7. The ability to design, create and use new elements for a product by its users (UGC) through a workshop in $\mathrm{OBCs}$ has a positive impact on the number of owners of that product.

\section{Research method}

\subsection{Research context}

Steam (http://store.steampowered.com/) is a popular video game OBC that was chosen to conduct this research. It is a digital distribution platform developed by Valve Corporation, which offers digital rights management for developers and multiplayer gaming for users. It is also configured as an OBC with social networking services. Additionally, Steam offers the possibility of using several Web APIs (available through the Steam official site). One of these 
APIs, called ISteamUserStats, is specially designed to collect data on Steam statistics from each game. Steamspy (http://steamspy.com/), a platform independent of Steam, uses this Web API in order to automatically gather data from Steam user profiles. Steamspy presents data in a simple and accurate manner and is designed to be helpful for all parties interested in PC gaming and its current state of affairs. Therefore, in order to collect data for this research, information from Steam and Steamspy were combined.

\subsection{Sampling and data collection}

The unit of analysis for this research is each game sold by Steam. Due to the high number of games distributed through this OBC, data collected by Steamspy were used to choose a sample of games. Following Smith et al. (2012), in order to maintain a manageable sampling scope, while still capturing a reasonably representative set of games, a restricted time frame was established: only games released during the month of June 2015, obtaining a final sample of 205 games. An independent coder, who had no knowledge of the research hypotheses, and one member of the research team manually collected UGC for each game (i.e., number of positive and negative comments, discussions, screenshots, artwork, videos, guides developed by users, whether the game had a workshop, as well as its price and genre) published between June 2015 and June 2016 in Steam. It must be noted that not only Steam users who own a game can generate UGC. All Steam users can navigate, access and create UGC throughout the entire community, including in the areas dedicated to each game, regardless of whether they own any of the them or not. Additionally, Steam users sometimes have a trial period and/or demos for certain games in order to test them before purchasing, with the possibility of creating UCG about their experiences. Moreover, Steam users can return a game already purchased and still have the opportunity to create UGC (applicable to those games with no more than two hours of playing time and returned within the first two weeks after purchase). Once the codification was completed, the assessment of the intercoder reliability was carried out using Holsti's reliability formula (Holsti, 1969), obtaining results above 0.80, thus displaying a high level of reliability (Neuendorf, 2002).

\subsection{Operationalization of the variables}

\subsubsection{Dependent variable}

The dependent variable included in the proposed model was extracted directly from Steamspy. Ideas from Thompson and Sinha (2008) regarding the impact of brand community membership on product adoption were used in this research as well. However, the measure of product adoption found in the aforementioned study was adapted in this research to serve as a counter of the number of owners of each game sold through Steam. Therefore, the number of owners can be considered a measure of performance or success of each product (i.e., game). It measures the estimated number of owners, and accounts for games bought on Steam, bought in retail stores and then activated on Steam, those bought in bundles, received through promotions or as a gift from other users. It also includes copies temporarily given away on 'free weekends'. This measure does not include games without Steamworks support sold on Origin (https://www.origin.com/en-gb/store/), Uplay (https://uplay.ubi.com/) or GOG (https://www.gog.com/) (i.e., they are different video games portals). Consequently, the number of owners is not a measure of revenue (because it excludes some sales) but it can be considered as a proxy of product success. 


\subsubsection{Independent variables}

The set of independent variables included in the proposed model was extracted directly from Steam. The main ideas of Jeon et al. (2016), who analyse the structure of content created by users in OBC, were adapted for the purposes of this research. The structure of UGC is linked to the concepts of vividness and richness in the present study, which herein codifies the types of media posts identified according to four levels of vividness (i.e., low level of vividness and richness, low-medium, medium-high, and high).

Low level of vividness and richness: positive and negative comments and discussions

Number of positive comments measures the number of positive comments that each game received from Steam users using a continuous variable.

Number of negative comments measures the number of negative comments that each game received from Steam users using a continuous variable.

Number of discussions measures the number of discussions or topics within the forum associated with each game received from Steam users. This variable is also codified as a continuous variable.

Low-medium level of vividness and richness: screenshots and artwork

Number of screenshots measures the number of screenshots of the game received from Steam users using a continuous variable. When a game received more than 1,000 screenshots from users, the amount of 1,001 was codified in the database (because the number of screenshots was manually counted). Proceeding in this way we maintained data collection scope manageable, while still capturing a reasonably representative set of this kind of UGC.

Amount of artwork measures the amount of creative material related to the game (but sometimes not directly extracted from the game, such as pictures, photos, T-shirt designs) received from Steam users using a continuous variable. Similar to the number of screenshots, when a game received more than 1,000 pieces of artwork from users, the amount of 1,001 was codified in the database.

Medium-high level of vividness and richness: videos and guides developed by users

Number of videos measures the number of videos (e.g., demos or playing instructions) shared by Steam users using a continuous variable. Similar to some of the previously described variables, when a game received more than 1,000 videos from users, the amount of 1,001 was codified in the database.

Number of guides measures the number of guides developed by Steam users that each game received using a continuous variable.

High level of vividness and richness: workshop presence

Workshop presence measures whether the game has a workshop using the value of 1 , or 0 otherwise. A workshop is an online space where Steam users can design, develop and offer other users elements specially created for the game. 


\section{Control variables}

Finally, as control variables (directly extracted from Steamspy) the price of the game and the genre of the game were included in this research. The price of the game was measured using a continuous variable (Chevalier and Mayzlin, 2006), while the genre of the game was measured using a categorical variable, taking the value of 1 for action games, 2 for adventure games, 3 for casual games, 4 for early availability games, 5 for free to play games, 6 for indie (independent) games, 7 for massive multiplayer games, 8 for races games, 9 for role playing games, 10 for simulators, 11 for sport games, 12 for strategic games, and finally 13 for utilities.

\subsection{Methodology applied}

The proposed model was analysed for potential multicollinearity problems. To test the absence of multicollinearity, bivariate correlation values and the variance inflation factor (VIF) were examined. Correlations with values above 0.8 indicate multicollinearity. In addition, individual VIF values greater than ten indicate a multicollinearity problem (Neter et al., 1989), along with average VIF values greater than five (Kleinbaum et al., 1988). Although variance inflation factor (VIF) scores were satisfactory overall, the relatively high correlations between some of the independent variables could make the results prone to multicollinearity (i.e., numbers of positive comments, negative comments, discussions, videos and guides, amount of artwork; see Table 1). Therefore, concurrent validity was assessed using ridge regression in favour of ordinary least squares (OLS) regression. Ridge regression addresses the principal multicollinearity symptom, high estimator variance, by systematic data manipulation. Specifically, this procedure involves the addition of successive larger constant terms to the matrix of correlations among the explanatory variables used in calculating the parameter coefficient estimates. Each addition is followed by the derivation of a set of estimates (Willis and Perlack, 1978). In short, the advantage of ridge regression is that it places a penalty on the size of the coefficients and is insensitive to correlations (Malthouse, 1999).

[Table 1. Descriptive statistics and correlations]

\subsection{Results}

Table 2 summarises the multivariate ridge regression results of the impact of different independent variables (i.e., the amount of UGC with low, low-medium, medium-high and high level of vividness and richness) and controls (i.e., price and genre) on the dependent variable (i.e., product success in terms of the number of owners of a product). These results show a high value for the coefficient of determination $\left(R^{2}=0.9128\right)$ and high beta weights overall. Out of the 10 betas, 8 are significant and only two display insignificant relationships (i.e., price and genre).

\section{[Table 2. Ridge regression results]}

With respect to the UGC characterised by a low level of vividness and richness, the amount of UGC in OBCs in the form of positive comments about a product appears to be significantly and positively associated with the number of owners of that product $(\beta=0.84, \mathrm{p}<0.01)$, supporting H1a. Similarly, the amount of UGC in OBCs in the form of negative comments about a product 
appears to be significantly and negatively associated with the number of owners of that product ( $\beta=-0.76, p<0.01$ ), supporting H1b. Therefore, the positive effect of the positive comments is stronger than the negative effect produced by negative comments on the number of owners. In relation to the amount of UGC in OBCs in the form of discussions about a product, it is significantly and negatively associated with the number of owners of that product $(\beta=-0.82$, $\mathrm{p}<0.01$ ), not supporting $\mathrm{H} 2$. Consequently, the negative effect of discussions is stronger than the effect of negative comments on the number of owners.

Regarding the UGC characterised by a low-medium level of vividness and richness, results on the amount of UGC in OBCs in the form of screenshots of a product is significantly and positively associated with the number of owners of that product $(\beta=0.17, \mathrm{p}<0.01)$, supporting H3. Results also indicate that the relationship between the amount of UGC in OBCs in the form of artwork and the number of owners of a product is significant and positive $(\beta=0.49, \mathrm{p}<0.01)$, supporting H4. Accordingly, the positive effect of artwork is stronger than the positive effect of screenshots on the number of owners.

With respect to the UGC characterised by a medium-high level of vividness and richness, the amount of UGC in OBCs in the form of videos showing the product does not have a positive impact on the number of owners of that product, and, on the contrary, this relationship is significant and negative $(\beta=-0.50, \mathrm{p}<0.01)$, not supporting H5. Additionally, the amount of UGC in OBCs in the form of guides about a product developed by users has a positive impact on the number of owners of that product $(\beta=1.41, \mathrm{p}<0.01)$, supporting H6. Therefore, the positive effect of guides developed by users is stronger than the negative effect of videos on the number of owners.

Finally, regarding the UGC characterised by a high level of vividness and richness, the possibility of designing, developing and offering other users new elements for a product through a workshop has a negative impact on the number of owners of this product $(\beta=-0.09, \mathrm{p}<0.01)$, not supporting $\mathrm{H} 7$.

\section{Discussion, conclusion and implications}

This study has analysed the impact of different types of UGC found in OBCs on the number of owners of products (i.e., a measure of product success). Steam, a major OBC associated with video games was chosen as the target for this study. The analysis performed using ridge regression confirms the influence of these different kinds of UGC on the number of owners.

\subsection{Discussion and theoretical implications}

Despite its importance for brand/product success, or the adoption of new brands/products, previous research has paid little attention to the study of a wide set of different kinds of UGC found in OBCs (Lamberton and Stephen, 2016; Yadav and Pavlou, 2014). Our analysis of the existing literature reveals that previous research is mainly focused on text-based customers' reviews and that analyses focused on different types of UGC merely explore its influence on brand popularity and brand engagement. This study offers a contribution to the literature by identifying, categorising and testing a wide set of different kinds of UGC in OBCs in order to determine whether they have any effect on product success. 
This study provides concrete ideas about the type of UGC in OBCs that significantly and positively predicts the success of products, such as the number of guides developed by users, positive comments, artwork and screenshots (in descending order). It has been demonstrated that the positive impact of the number of guides developed by users on product success, characterised by a medium-high level of vividness and richness in this research, are in line with the results of Jeon et al. (2016) and Xu et al. (2009), who determine that this kind of UGC has a positive impact on the reaction of users and also attracts new users. Similarly, the number of positive comments, with a low level of vividness and richness, is a strong motivator of product success, corroborating the view of Adjei et al. (2010) or Chevalier and Mayzlin (2006). Moreover, artwork and screenshots, with a low-medium level of vividness and richness, greatly promote product success as well, corroborating the ideas of Adjei et al. (2010), Gruner et al. (2014) or Thompson and Sinha (2008).

Finally, this study also provides specific ideas about the type of UGC that significantly and negatively impacts the success of products, such as the number of discussions, negative comments, videos and workshop presence (in descending order). In particular, the number of negative comments, with a low level of vividness and richness, acts as a strong inhibitor of product success. This result corroborates the ideas of Luo (2009) about negative e-WOM, which refers to unfavourable experience and recommendations related to not buying certain products. Additionally, as the type of UGC becomes more complex, results show that users do not guide their choices based on UGC which take longer to be understood (i.e., discussions, videos) or need more involvement (i.e., workshop presence). In this regard, the number of discussions, considered in this research to be in the low level of vividness and richness, acts as another inhibitor of product success, not corroborating the view of Thompson and Sinha (2008). This result can be explained by the idea that users have to read the whole thread of the conversation in order to understand a discussion (i.e., it is a time-consuming process). In line with Jeon et al. (2016), despite being able to offer richer information, results obtained in this research also show that videos have a negative impact on the number of owners of products. Users also have to watch an entire video in order to understand its content (i.e., it is also a time-consuming process). Finally, despite the fact that workshop presence has been linked in this research to a high degree of vividness and richness, this variable also acts as an inhibitor of product success, not corroborating the view of Fortin and Dholakia (2005), Lohtia et al. (2007) or Coursaris et al. (2016). Users have to be highly involved in a game to interact with the workshop and create or use some of the UGC provided in that particular section. Therefore, we can conclude that a workshop is not an effective way to attract potential customers, and can be more useful only to expert owners of a game.

\subsection{Managerial implications}

Understanding the relationship between consumers and brands in OBCs has powerful managerial implications as the sharing of personal views and opinions of brands in OBCs have an ever-increasing influence on other customers (Wang et al., 2011). Therefore, managers should consider paying attention to the different types of UGC in order to achieve the greatest positive outcome from their presence in OBCs. With the aim of helping managers in this task, this research proposes and tests a framework including a comprehensive typology of UGC based on richness and vividness concepts. Thus, the proposed framework can help managers to better understand the diversity of messages that can be used in OBCs. Additionally, this research offers an analytical tool for assessing the impact of different types of UGC on product 
success. In particular, based on the results obtained, the type of UGC that exerts the highest positive effect on product success is the number of guides developed by users (characterised by a medium-high level of vividness and richness), while the number of discussions (characterised by a low level of vividness and richness) exerts the highest negative effect on product success. Finally, the findings of this research suggest managers focus their marketing efforts regarding OBCs on encouraging consumers to create the type of UGC that most positively affects product success.

\subsection{Limitations and future research directions}

This paper has some limitations, which calls for future research. First, despite the fact that Steam is a global OBC and is able to collect differences in cultural and economic environments around the world, this study has merely targeted one OBC (Steam). This community is specialised in video games and no other sectors of activity were included in this research. Therefore, care needs to be taken when attempting to generalise the results obtained and when subsequently extending them to other contents not related to the video game industry. Future research streams also need to be conducted using other sectors of activity. Second, this study only includes information about the UGC within OBCs; the model does not include the users' reactions to the UGC or how other users react to the content found in OBCs (Schlosser, 2005). Consequently, the inclusion of user reactions to UGC displays potential as an interesting future research stream. Finally, this study only includes quantitative variables and does not reflect valence of discussions and other qualitative or subjective content included in comments. The use of text and visual mining (i.e., the analysis of the information contained in different types of messages depicted in $\mathrm{OBCs}$ ) in order to categorise the content of messages may also be a useful extension of this work.

\section{References}

Adjei, M.T., Noble, S.M. and Noble, C.H. (2010), "The influence of C2C communications in online brand communities on customer purchase behaviour", Journal of the Academy of Marketing Science, Vol. 38 No. 5, pp. 634-653.

Ailawadi, K.L and Farris, P.W. (2017), "Managing Multi-and Omni-Channel Distribution: Metrics and Research Directions", Journal of Retailing, Vol. 93 No. 1, pp. 120-135.

Bagozzi, R.P. and Dholakia, U.M. (2006), "Antecedents and purchase consequences of customer participation in small group brand communities", International Journal of Research in Marketing, Vol. 23, pp. 45-61.

Ballestar, M.T., Grau-Carles, P. and Sainz, J. (2016), "Consumer behavior on cashback websites: Network strategies”, Journal of Business Research, Vol. 69 No. 6, pp. 2101-2107.

Batra, R. and Keller, K.L. (2016), "Integrating Marketing Communications: New Findings, New Lessons, and New Ideas", Journal of Marketing, Vol. 80 No. 6, pp. 122-145.

Bellman, S., Johnson, E., Lohse, G. and Mandel, N. (2006), "Designing marketplaces of the artificial with consumers in mind: four approaches to understanding consumer behavior in electronic environments", Journal of Interactive Marketing, Vol. 20 No. 1, pp. 21-33. 
Berthon, P., Pitt, L. and Campbell, C. (2008), "Ad Lib: When Customers Create the Ad," California Management Review, Vol. 50 No. 4, pp. 6-30.

Burmann, C. (2010), “A Call for 'User-Generated Branding'," Journal of Brand Management, Vol. 18 No. 1, pp. 1-4.

Chang, A., Hsieh, S.H. and Tseng, T.H. (2013), "Online brand community response to negative brand events: the role of group eWOM", Internet Research, Vol. 23 No. 4, pp. 486-506.

Chari, S., Christodoulides, G., Presi, C., Wenhold, J. and Casaletto, J. P. (2016), "Consumer Trust in User-Generated Brand Recommendations on Facebook", Psychology \& Marketing, Vol. 33 No. 12, pp. 1071-1081.

Chevalier, J.A. and Mayzlin, D. (2006), "The effect of word of mouth on sales: Online book reviews", Journal of Marketing Research, Vol. 43 No. 3, pp. 345-354.

Cotte, J. and LaTour, K.A. (2009), "Blackjack in the Kitchen: Understanding Online Versus Casino Gambling”, Journal of Consumer Research, Vol. 35 No. 5, pp. 742-758.

Coursaris, C.K., van Osch, W. and Balogh, B. A. (2016), "Informing brand messaging strategies via social media analytics”, Online Information Review, Vol. 40 No. 1, pp. 6-24.

Coyle, J.R. and Thorson, E. (2001), "The effects of progressive levels of interactivity and vividness in web marketing sites", Journal of Advertising, Vol. 30 No. 3, pp. 65-77.

Daft, R.L. and Lengel, R.H. (1986), "Organizational information requirements, media richness and structural design", Management Science, Vol. 32 No. 5, pp. 554-571.

Dessart, L., Veloutsou, C. and Morgan-Thomas, A. (2015), "Consumer engagement in online brand communities: a social media perspective", Journal of Product \& Brand Management, Vol. 24 No. 1, pp. 28-42.

De Vries, L., Gensler, S. and Leeflang, P.S. (2012), "Popularity of brand posts on brand fan pages: An investigation of the effects of social media marketing", Journal of Interactive Marketing, Vol. 26 No. 2, pp. 83-91.

Floyd, K., Freling, R., Alhoqail, S., Cho, H.Y. and Freling, T. (2014), "How Online Product Reviews Affect Retail Sales: A Metaanalysis”, Journal of Retailing, Vol. 90 No. 2, 217-232.

Fortin, D.R. and Dholakia, R.R. (2005), "Interactivity and vividness effects on social presence and involvement with a web-based advertisement", Journal of Business Research, Vol. 58 No. 3, pp. 387-396.

Ghose, A. and Ipeirotis, P. (2009), "The EconoMining project at NYU: Studying the economic value of user-generated content on the internet", Journal of Revenue \& Pricing Management, Vol. 8 No. 2, pp. 241-246. 
Gruner, R.L., Homburg, C. and Lukas, B.A. (2014), "Firm-hosted online brand communities and new product success", Journal of the Academy of Marketing Science, Vol. 42 No. 1, pp. 2948.

Hennig-Thurau, T., Gwinner, K.P., Walsh, G. and Gremler, D.D. (2004), "Electronic word-ofmouth via consumer-opinion platforms: What motivates consumers to articulate themselves on the Internet?", Journal of Interactive Marketing, Vol. 18 No. 1, pp. 38-52.

Holsti, O.R. (1969), Content Analysis for the Social Sciences and Humanities, Reading, Addison-Wesley, MA.

Huang, P., Lurie, N.H. and Mitra, S. (2009), "Searching for Experience on the Web: An Empirical Examination of Consumer Behavior for Search and Experience Goods", Journal of Marketing, Vol. 73 No. 2, pp. 55-69.

Jeon, H., Ahn, H.J and Yu, G. J. (2016), "What makes people react to the posts on the brand pages of mobile social network games?", Online Information Review, Vol. 40 No. 3, pp. 435448.

Kaplan, A.M. and Haenlein, M. (2010), "Users of the world, unite! The challenges and opportunities of social media”, Business Horizons, Vol. 53 No. 1, pp. 59-68.

Kleinbaum, D.G., Kupper, L.L. and Muller, K.E. (1988), Applied regression analysis and other multivariate analysis methods, PWS-Kent Publishing Company, Boston.

Kumar, A., Bezawada, R., Rishika, R., Janakiraman, R. and Kannan, P.K. (2016), "From Social to Sale: The Effects of Firm-Generated Content in Social Media on Customer Behavior", Journal of Marketing, Vol. 80 No. 1, pp. 7-25.

Lamberton, C. and Stephen, A.T. (2016), "A Thematic Exploration of Digital, Social Media, and Mobile Marketing: Research Evolution from 2000 to 2015 and an Agenda for Future Inquiry", Journal of Marketing, Vol. 80 No. 6, pp. 146-172.

Lohtia, R., Donthu, N. and Yaveroglu, I. (2007), "Evaluating the efficiency of Internet banner advertisements", Journal of Business Research, Vol. 60 No. 4, pp. 365-370.

Luarn, P., Lin, Y.F. and Chiu, Y.P. (2015), "Influence of Facebook brand-page posts on online engagement”, Online Information Review, Vol. 39 No. 4, pp. 505-519.

Luo, X. (2009), "Quantifying the long-term impact of negative word of mouth on cash flows and stock prices", Marketing Science, Vol. 28 No. 1, pp.148-165.

Malthouse, E.C. (1999), "Ridge regression and direct marketing scoring models", Journal of Interactive Marketing, Vol. 13 No. 4, pp. 10-23.

Möller, K. (2013), "Theory map of business marketing: Relationships and networks perspectives", Industrial Marketing Management, Vol. 42 No. 3, pp. 324-335. 
Mutaz, M.A., Mamoun, N.A. and Ashouri, M.I. (2015), "Consumer attitudes towards online shopping: the effects of trust, perceived benefits, and perceived web quality", Internet Research, Vol. 25 No. 5, pp. 707-733.

Neter, J., Wasserman, W. and Kutner, M.H. (1989), Applied Regression Models, Irwin, Homewood, IL.

Neuendorf, K. (2002), The Content Analysis Guidebook, Sage, Thousand Oaks, CA.

Pazgal, A. and Soberman, D. (2008), "Behavior-Based Discrimination: Is It a Winning Play, and If So, When?”, Marketing Science, Vol. 27 No. 6, pp. 977-994.

PCGamer (2016), "The 2016 Steam Summer Sale was a smashing success", available at: http://www.pcgamer.com/the-2016-steam-summer-sale-was-a-smashing-success/

Purnawirawan, N., Eisend, M., De Pelsmacker, P. and Dens, N. (2015), "A Meta-analytic Investigation of the Role of Valence in Online Reviews", Journal of Interactive Marketing, Vol. 31, pp. 17-27.

Rauschnabel, P.A., Praxmarer, S. and Ivens, B.S. (2012), "Social media marketing: how design features influence interactions with brand postings on Facebook", in Eisend, M., Langner, T. and Okazaki, S. (Eds), Advances in Advertising Research, Vol. III, Springer Gabler, Germany, pp. 153-161.

Ringel, D.M. and Skiera, B. (2016), "Visualizing asymmetric competition among more than 1,000 products using big search data”, Marketing Science, Vol. 35 No. 3, pp. 511-534.

Sabate, F., Berbegal-Mirabent, J., Cañabate, A. and Lebherz, P.R. (2014), "Factors influencing popularity of branded content in Facebook fan pages", European Management Journal, Vol. 32 No. 6, pp. 1001-1011.

Saboo, A.R., Kumar, V. and Ramani, G. (2015), "Evaluating the impact of social media activities on human brand sales", International Journal of Research in Marketing, in press.

Schlosser, A.E. (2005), "Posting Versus Lurking: Communicating in a Multiple Audience Context", Journal of Consumer Research, Vol. 32 No. 2, pp. 260-65.

Smith, A. N., Fischer, E. and Yongjian, C. (2012), "How does brand-related user-generated content differ across YouTube, Facebook, and Twitter?", Journal of Interactive Marketing, Vol. 26 No. 2, pp. 102-113.

Statista (2016), "Value of the global video game market", available at: http://www.statista.com/statistics/246888/value-of-the-global-video-game-market/

Steinmann, S., Mau, G. and Schramm-Klein, H. (2015), "Brand Communication Success in Online Consumption Communities: An Experimental Analysis of the Effects of Communication Style and Brand Pictorial Representation”, Psychology \& Marketing, Vol. 32 No. 3, pp. 356371. 
Steuer, J. (1992), "Defining virtual reality: dimensions determining telepresence", Journal of Communication, Vol. 42 No. 4, pp. 73-93.

Stokburger-Sauer, N. (2010), "Brand community: drivers and outcomes", Psychology \& Marketing, Vol. 27 No. 4, pp. 347-368.

Thompson, S.A. and Sinha, R.K. (2008), "Brand communities and new product adoption: The influence and limits of oppositional loyalty". Journal of Marketing, Vol. 72 No. 6, pp. 65-80.

Veloutsou, C., Aldas-Manzano, J. and Ruiz-Mafe, C. (2017), "The Dual Nature of Spreading Negative eWOM for Branded Offers: Emotional Reaction or Social Response? A Structured Abstract", in Stieler M. (Ed.), Creating Marketing Magic and Innovative Future Marketing Trends, Springer, Cham, pp. 471-476.

Wang, Y.J., Butt, O.J., and Wei, J. (2011), "My identity is my membership: A longitudinal explanation of online brand community members' behavioural characteristics", Journal of Brand Management, Vol.19 No. 1, pp 45-56.

Wesley, D. and Barczak, G. (2016), Innovation and marketing in the video game industry: avoiding the performance trap, Routledge, New York.

Wilbur, K.C. and Yi, Z. (2009), “Click Fraud”, Marketing Science, Vol. 28 No. 2, pp. 293-308.

Willis, C.E. and Perlack, R. D. (1978), "Multicollinearity: effects, symptoms, and remedies", Journal of the Northeastern Agricultural Economics Council, Vol. 7, pp. 55-61.

Xu, H., Oh, L.B. and Teo, H.H. (2009), "Perceived effectiveness of text vs. multimedia location-based advertising messaging", International Journal of Mobile Communications, Vol. 7 No. 2, pp. 154-177.

Yadav, M.S. and Pavlou, P.A. (2014), "Marketing in computer-mediated environments: Research synthesis and new directions”, Journal of Marketing, Vol. 78 No. 1, pp. 20-40.

You, Y., Vadakkepatt, G.G. and Joshi, A.M. (2015), “A Metaanalysis of Electronic Word-ofmouth Elasticity," Journal of Marketing, Vol. 79 No. 2, 19-39.

Zhang, J. and Wedel, M. (2009), "The Effectiveness of Customized Promotions in Online and Offline Stores”, Journal of Marketing Research, Vol. 46 No. 2, pp. 190-206. 


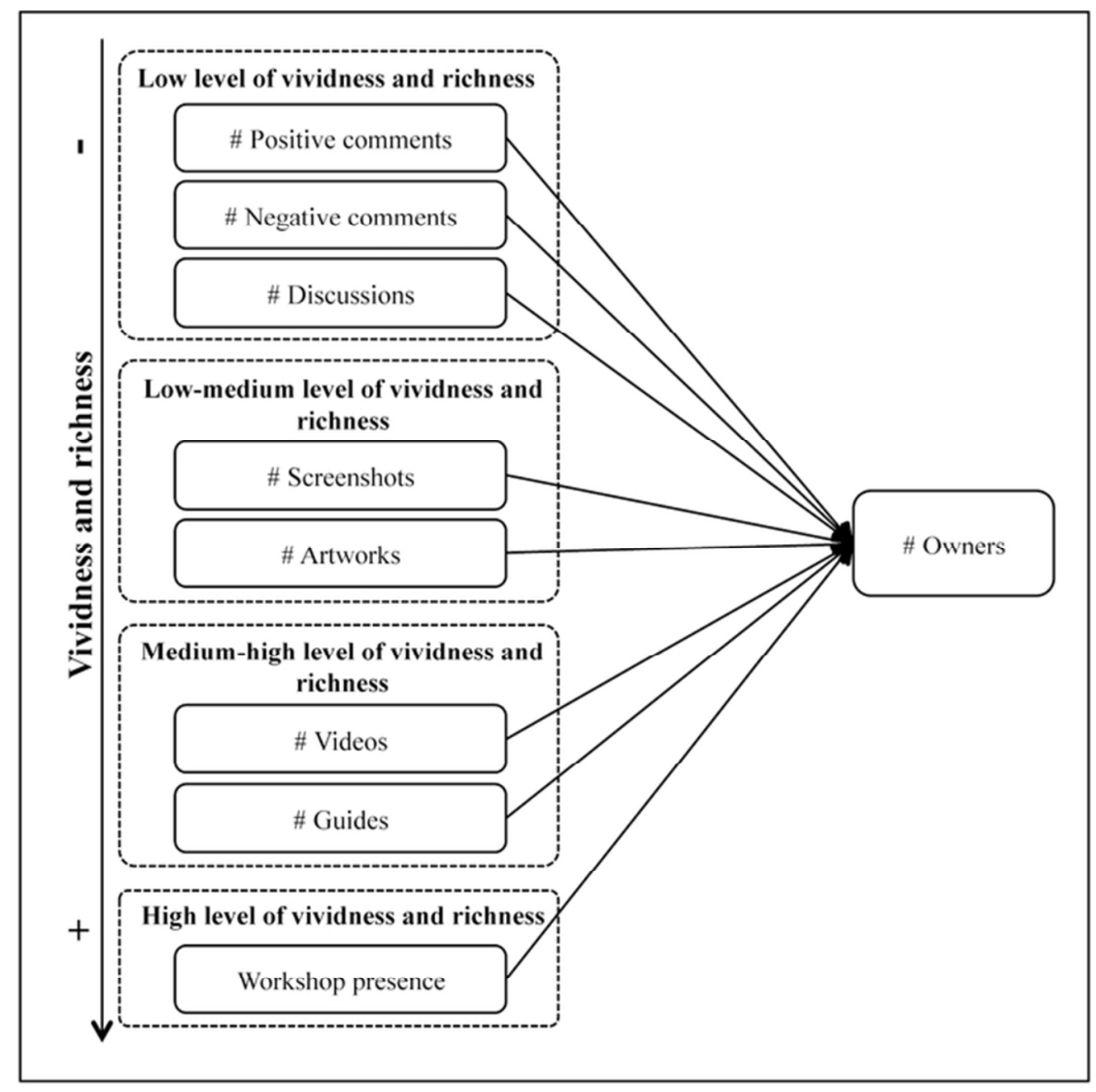

Figure 1. Research model $119 \times 119 \mathrm{~mm}(150 \times 150 \mathrm{DPI})$ 
Table 1. Descriptive statistics and correlations

\begin{tabular}{|c|c|c|c|c|c|c|c|c|c|c|c|}
\hline \multirow{2}{*}{ 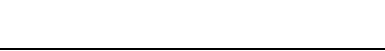 } & \\
\hline & Mean & S.D. & 1 & 2 & 3 & 4 & 5 & 6 & 7 & 8 & 9 \\
\hline 1. Number of positive comments & 739.06 & $4,360.90$ & & & & & & & & & \\
\hline 2. Number of negative comments & 294.07 & $1,806.87$ & 0.910 & & & & & & & & \\
\hline 3. Number of discussions & 111.34 & 478.30 & 0.936 & 0.790 & & & & & & & \\
\hline 4. Number of screenshots & 273.10 & 371.95 & 0.301 & 0.301 & 0.313 & & & & & & \\
\hline 5. Number of artworks & 26.68 & 126.52 & 0.822 & 0.820 & 0.633 & 0.384 & & & & & \\
\hline 6. Number of videos & 45.82 & 142.39 & 0.758 & 0.720 & 0.594 & 0.537 & 0.932 & & & & \\
\hline 7. Number of guides & 6.70 & 33.05 & 0.977 & 0.895 & 0.879 & 0.356 & 0.864 & 0.811 & & & \\
\hline 8. Workshop presence & n.a. & n.a. & 0.282 & 0.197 & 0.334 & 0.300 & 0.256 & 0.307 & 0.311 & & \\
\hline 9. Price & 9.08 & 9.40 & 0.172 & 0.180 & 0.220 & 0.332 & 0.205 & 0.288 & 0.183 & 0.202 & \\
\hline 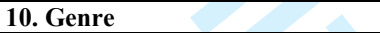 & n.a. & n.a. & -0.100 & -0.129 & -0.072 & -0.020 & -0.096 & -0.102 & -0.104 & -0.042 & 0.086 \\
\hline
\end{tabular}

Note: n.a. not applicable

16

17

18

19

20

21

22

23

24

25

26

27

28

29

30

31

32

33

34

35

36

37

38

39

40

41

42

43

44

45

46

47

48

49

50

51

52

53

54

55

56

57

58

59 
Table 2. Ridge regression results

\begin{tabular}{lcc}
\hline Independent variables & $\boldsymbol{\beta}$ & S.E. \\
\hline $\begin{array}{l}\text { Number of positive } \\
\text { comments }\end{array}$ & $0.84^{*}$ & 0.24 \\
\hline $\begin{array}{l}\text { Number of negative } \\
\text { comments }\end{array}$ & $-0.76^{*}$ & 0.06 \\
\hline Number of discussions & $-0.82^{*}$ & 0.11 \\
\hline Number of screenshots & $0.17^{*}$ & 0.03 \\
\hline Amount of artwork & $0.49^{*}$ & 0.08 \\
\hline Number of videos & $-0.50^{*}$ & 0.08 \\
\hline Number of guides & $1.41^{*}$ & 0.13 \\
\hline Workshop presence & $-0.09^{*}$ & 0.02 \\
\hline Control variables & & \\
\hline Price & -0.03 & 0.02 \\
\hline Genre & 0.02 & 0.02 \\
\hline Note: &
\end{tabular}

Note: standardised $\beta$ coefficients

${ }^{*} \mathrm{p}<0.01 ; * * \mathrm{p}<0.05 ; * * * \mathrm{p}<0.1$ 